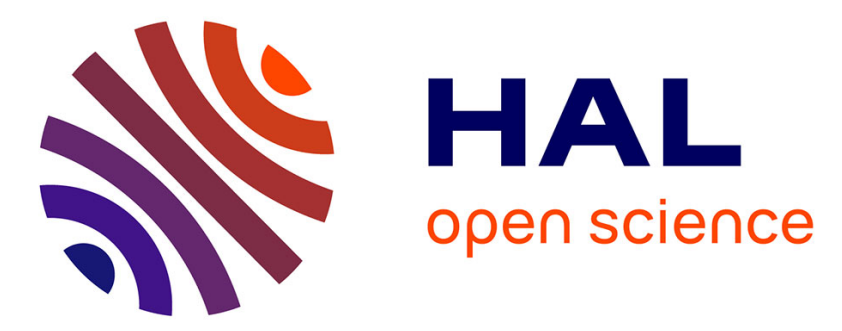

\title{
Field and Frequency Dependences of Mono- and Multidomain microwave Absorption in Magnetic Films
}

\author{
N. Vukadinovic, J. Ben Youssef, H. Le Gall, J. Desvignes
}

\section{To cite this version:}

N. Vukadinovic, J. Ben Youssef, H. Le Gall, J. Desvignes. Field and Frequency Dependences of Monoand Multidomain microwave Absorption in Magnetic Films. Journal de Physique IV Proceedings, 1997, 07 (C1), pp.C1-453-C1-454. 10.1051/jp4:19971184 . jpa-00254833

\section{HAL Id: jpa-00254833 https://hal.science/jpa-00254833}

Submitted on 1 Jan 1997

HAL is a multi-disciplinary open access archive for the deposit and dissemination of scientific research documents, whether they are published or not. The documents may come from teaching and research institutions in France or abroad, or from public or private research centers.
L'archive ouverte pluridisciplinaire HAL, est destinée au dépôt et à la diffusion de documents scientifiques de niveau recherche, publiés ou non, émanant des établissements d'enseignement et de recherche français ou étrangers, des laboratoires publics ou privés. 


\title{
Field and Frequency Dependences of Mono- and Multidomain microwave Absorption in Magnetic Films
}

\author{
N. Vukadinovic, J. Ben Youssef*, H. Le Gall* and J.M. Desvignes* \\ DGT/DTA/EM, Dassault Aviation, 92252 Saint-Cloud, France \\ * CNRS - LMIMS, 92195 Meudon - Bellevue, France
}

\begin{abstract}
We report both experimental and theoretical results concerning the applied dc field dependence of microwave absorption on mono and multidomain structures. Especially, we are interested in the low-field region where this absorption is due to the domain mode ferromagnetic resonance (DM-FMR) phenomenon. The sample supporting parallel stripe domains is a rare earth bismuthsubstituted single-crystal garnet film. We study the variation of DM-FMR microwave power absorption as a function of the strength of the dc field applied in the domain wall plane inside the frequency range 6-11 GHz using a highly sensitive FMR spectrometer. The power absorption spectra $\mathrm{Pa}(\mathrm{H})$ present complex shapes in the low-field region with one or two peaks. The experimental results are analyzed by adopting the formalism of Smit and Beljers. This model seems inadequate to describe precisely the whole observed behaviours and such a discrepancy will be discuss.
\end{abstract}

\section{INTRODUCTION}

In order to identify the mechanisms of microwave absorption in ferrimagnetic materials, many experiments were performed in the ideal case of single-crystal garnet films with a high uniaxial anisotropy field and supporting parallel stripe domains. In this simple configuration, several kinds of magnetic excitations such as domain wall resonances and domain mode ferromagnetic resonances (DM-FMR) were observed.

The DM-FMR are due to the gyromagnetic phenomenon perturbated by the multidomain structure as predicted by Polder and Smit [1]. In the case of parallel stripe domains, two modes denoted $\omega^{-}$and $\omega^{+}[2]$ can be excited according to the orientation of the If magnetic field $h$ either parallel ( $\omega^{+}$mode) or perpendicular ( $\omega^{-}$mode) to the stripe direction. The DM-FMR dynamic susceptibility can be computed by using the Smit -Beljers (S-B) theory [3]. Satisfactory agreements between experimental and theoretical results are reported concerning the zero-field DM-FMR microwave absorption [4].

In this paper, we study microwave power absorption spectra $\mathrm{Pa}(\mathrm{H})$ where $\mathrm{H}$ is a planar dc field. The experimental field and frequency dependences of microwave absorption are analyzed in light of S-B model.

\section{MATERIAL AND EXPERIMENTAL PROCEDURE}

The sample used in this study was rare earth bismuth-substituted single-crystal garnet film (YSmLuBiCa) $)_{3}(\mathrm{FeSi})_{5} \mathrm{O}_{12}$ grown by LPE on a (111)-oriented GGG substrate. The main magnetic parameters were : the saturation induction $4 \pi \mathrm{M}_{S}=1420 \mathrm{G}$, the uniaxial anisotropy field $\mathrm{H}_{\mathrm{KU}}=2180 \mathrm{Oe}$, the damping parameter $\alpha=0.07$ and the gyromagnetic ratio $\gamma=1.92 \mathrm{~s}^{-1} \mathrm{Oe}^{-1}$. The remanent domain structure corresponded essentially to parallel stripe domains characterized by the aspect ratio $P_{0} / t$ where $P_{0}$ is the zero-field stripe period and $t$ is the film thickness.

The microwave absorption experiments were performed in the frequency range $6-11 \mathrm{GHz}$ using a highly sensitive FMR spectrometer with a non-resonant microstrip transmission line in a planar field-swept configuration. The shape of planar microstrip excitation line induces a rf magnetic field $\mathrm{h}$ in the film plane. The in-plane dc field $\mathrm{H}$ was along the stripe direction.

\section{MAIN RESULTS AND DISCUSION}

The recorded power absorption spectra $\mathrm{Pa}(\mathrm{H})$ exhibit the following characteristics :

- in the unsaturated region for the frequency $\mathrm{f}<8.5 \mathrm{GHz}$ two peaks are clearly observed (Fig.1a)). As the frequency increases the resonance fields $\mathrm{H}_{\mathrm{rl}}, \mathrm{H}_{\mathrm{r} 2}$ associated with these two peaks are shifted towards lower fields. The shift is more important in the case of the resonance peak $\mathrm{H}_{\mathrm{xl}}$ at the low-field side (Fig. 2). For $f \geq 8.5 \mathrm{GHz}$ only one peak is noted whose resonance field decreases with increasing of the frequency (Fig.1 b)) 
- in the saturated region the classical enhancement of the $\mathrm{FMR}_{/ /}$field with increasing of the frequency is observed.

The experimental spectra are analyzed in light of the extended S-B theory $[4,5]$. For each value of $H$, the computation procedure is the following:

- determination of the period and the demagnetization factor $\mathrm{N}_{Z Z}$ of the parallel stripe domains structure

- calculation of the DM-FMR dynamic susceptibility $\chi=\chi^{\prime}-j \chi^{\prime \prime}$ from the Landau-Lifshitz equation :

The calculated spectra $\mathrm{Pa}(\mathrm{H})=\frac{1}{2} \omega h^{2} \chi^{\prime \prime}(\mathrm{H})$ are displayed for two frequencies $\mathrm{f}=8$ and $10 \mathrm{GHz}$ in Figs $\left.\left.1 \mathrm{a}\right), \mathrm{b}\right)$.

At $8 \mathrm{GHz}$ the theory predicts the existence of the only $\omega^{+}$mode which is not consistent with the two experimentally observed peaks. Such a discrepancy was first pointed out by $\mathrm{Bi}[6]$ who studied the effect of the rf magnetic field orientation with respect to the stripe direction on the DM-FMR absorption. In the presence of a sufficiently strong magnetic dc field $\mathrm{H}$ parallel to the stripe direction, a splitting of the $\omega^{+}$mode into two subpeaks was observed when a rf magnetic field component parallel to the stripe direction exists. Such conditions are verified in our experiments.

At $10 \mathrm{GHz}$ the absorption occurs at near zero field. A satisfactory agreement is obtained with the $\omega^{+}$mode absorption deduced from the theory.

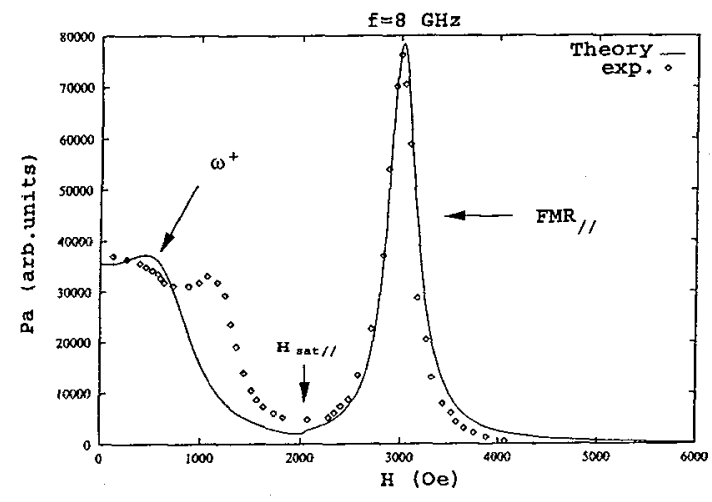

a)

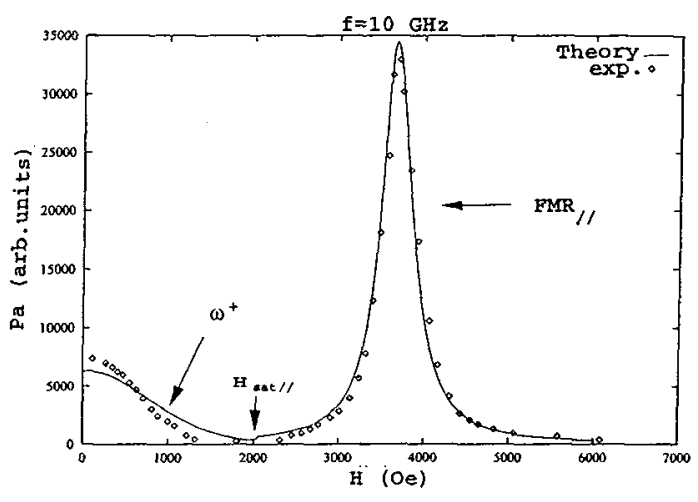

b)

Figure 1: Experimental (dots) and theoretical (solid line) microwave power absorption $\mathrm{Pa}$ as a function of the in-plane field $\mathrm{H}$ : a) $\mathrm{f}=8 \mathrm{GHz}$, b) $\mathrm{f}=10 \mathrm{GHz}$.

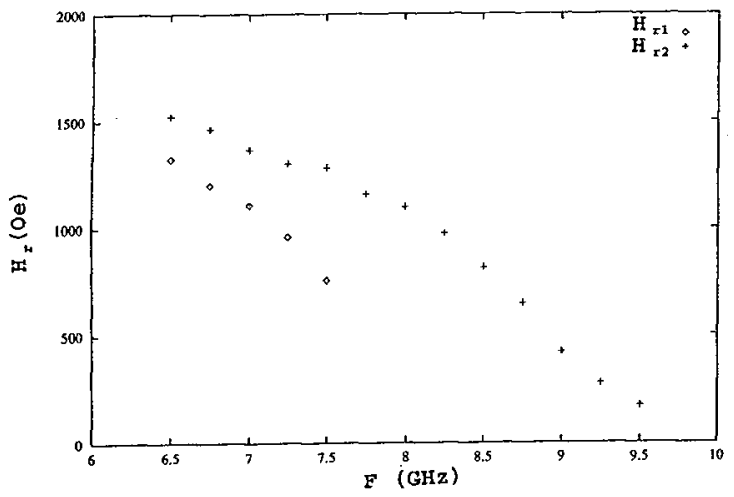

Figure 2: Experimental frequency dependence of resonance fields in the unsaturated region

\section{CONCLUSION}

In this study, it is shown that even in the simple parallel stripe domains structure the power absorption spectra $\mathrm{Pa}$ (H) present complex shapes in the low-field region with one or two peaks. The extended S-B theory appears inadequate to describe the whole observed behaviours. A further investigation is in progress to understand the origin of the DM-FMR splitting.

\section{References}

[1] D. Polder, J. Smit, Rev. Mod. Phys 25 (1953) 89-90

[2] J.O. Artman, Phys. Rev. 105 (1957) 74 -84

[3] J. Smit, S. Beljers, Philips Res. Rep.10 (1955) 113-130

[4] N. Vukadinovic, J. Ben Youssef, H. Le Gall, J.Magn. Magn. Mater. 150 (1995) 213-222

[5] J.O. Artman, S. H. Charap, J. Appl. Phys. 49 (1978) 1587-1589

[6] S. Bi, J. Appl. Phys. 67 (1990) 3179-3181 